\title{
An analysis of Comrades marathon records: A 2008 update
}

\author{
A N Bosch (PhD) \\ MRC/ UCT Research Unit for Exercise Science and Sports Medicine, University of Cape Town Sports Science Institute of South Africa
}

The Comrades marathon is an ultra-distance race held annually between Durban and Pietermaritzburg in South Africa. An interesting feature of this race is that the direction alternates each year between the two cities, with the run from Durban to Pietermaritzburg being uphill in nature, while the 'down' run from Pietermaritzburg to Durban is, conversely, predominantly downhill in nature. Because of this it can be expected that different runners may excel at one or the other 'direction' and that the times will differ between 'up' and 'down' races. This is, indeed, the case, albeit with a few exceptions.

In 2004, the South African Journal of Sports Medicine (SA J Sports Med 2004; 16(3): 26-27) published a commentary analysing Comrades marathon records by running speed rather than race time, as the race distance varies considerably from year to year and finishing times do not therefore indicate who really have run the fastest over the course.

Since the start and finish areas are different in each city, the distance of each race is different. This is compounded by the race being almost $90 \mathrm{~km}$ long, making changes in the route due to road works, road changes and local authorities, inevitable. It is therefore not surprising that the distance of the race varies even over the same direction, i.e. neither the 'up' nor 'down' runs are constant in distance. All of this makes the question of race records and fastest times over the route a difficult one.

Because of the fundamental differences in the nature of the 'up' and 'down' runs, each lends itself naturally to its own 'record' times. Thus the issue that remains is that of the variation in race distance over a particular direction, which has, at times, varied by more than a kilometre. For practical purposes, the fastest time run is regarded as the record regardless of the distance. However, a more in-depth analysis of the times run over the route is interesting since the quickest time to complete the race might not necessarily equate to the fastest running speed over the course if expressed as km.hr ${ }^{-1}$ or minutes and seconds per kilometre, as indicated in the opening paragraphs. For example, in 1986 Bruce Fordyce ran what was then the fastest time for the 'down' race $(5 \mathrm{~h} 24 \mathrm{~min} 07 \mathrm{~s})$, which was 88.77 $\mathrm{km}$ long. However, he had run $5 \mathrm{~h} 27 \mathrm{~min} 18 \mathrm{~s}$ in the 1984 down run, which was $89.75 \mathrm{~km}$ long. Thus although the race that year was a kilometre longer, his time was only 3 minutes 11 seconds slower. If we look at his running speed, this was actually higher in 1984 due to the longer distance of the race that year. And what of the run by Alan Robb in 1978 when the race was $90.1 \mathrm{~km}$ long and his time $5 \mathrm{~h} 29$ $\min$ ? And where do the two recent fastest times of the Russian,

\section{CORRESPONDENCE:}

\author{
A N Bosch \\ MRC/UCT Research Unit for Exercise Science and Sports \\ Medicine \\ Sports Science Institute of South Africa \\ Boundary Road \\ 7700 Newlands \\ Tel: 2721 650-4578 \\ Fax: 2721 686-7530 \\ E-mail: andrew.bosch@uct.ac.za
}

Leonid Shvetsov slot in? It is therefore interesting to calculate the actual running speed of the top runners, using the race distances of each specific year. Although such calculations do not take into account that the latter kilometres of the race will probably be run slower than the average speed maintained during the race, it is unlikely that the overall picture will be incorrect as this will have been the same for all the runners concerned. Another complication in doing such an analysis is that only recently has the course been accurately measured, and this could affect the outcome of calculations of race speed and rankings.

The fastest times (h: min: s) recorded for the 'down' run are shown below:
1. L. Shvetsov
5: 20: 41 (2007)
2. B. Fordyce
5: 24: 07 (1986)
3. A. Kelehe
5: 25: 51 (2001)
4. B. de la Motte
5: $26: 12$ (1986)
5. L. Shvetsov
5: $26: 28(2001)$
6. B. Fordyce
5: $27: 18(1984)$

It is noteworthy that the times run in 1986 and 2001 account for four of the five fastest times in which the race has been run. This is probably due to Bruce Fordyce and Bob de la Motte (see list above) having a 'man on man' race in the third quarter of the 1986 race, which resulted in a very fast pace. Similarly, in the 2001 race a fast 'breakaway group' also resulted in fast times as the eventual winner, Andrew Kelehe, had to run at a fast pace to catch the leaders and then continued at that pace after catching and passing them. Since the original article was written in 2004, it is the presence of Shvetsov in the race that has made an update necessary, as he has subsequently run record times for both the 'down' and 'up' races.

The order of the top runners looks somewhat different from that given in the previous paragraph when the running speed of each runner for each race is calculated. These results are shown in Table I.

Shvetov has replaced Fordyce as having the fastest speed for the race by the rather substantial margin of 3 seconds. $\mathrm{km}^{-1}$. Fordyce, however, still has the second, third and sixth fastest speeds of all time and still dominates the list by claiming three of the fastest six running speeds over the course.

If we consider athletes rather than performances, i.e. if only the best time of each athlete is considered, then the fastest runners on the 'down' run have been Shvetsov $\left(3: 35.5 . \mathrm{km}^{-1}\right)$, Fordyce $\left(3: 38.8 . \mathrm{km}^{-1}\right)$, Robb (3:39.2. $\left.\mathrm{km}^{-1}\right)$, Mattheus $\left(3: 39.3 . \mathrm{km}^{-1}\right)$, and Kelehe $\left(3: 39.7 . \mathrm{km}^{-1}\right)$. Only Shvetsov is not South African.

Since it is somewhat difficult to perceive the implications of a difference in running speed of $3: 35.5 . \mathrm{km}^{-1}$ at the top of the table and $3: 39.5 \mathrm{~km}^{-1}$ at the bottom, these speeds can be used to normalise the times that would have been run by these athletes over a hypothetical race of standard distance. Since the average distance of the 'down' race in Table I has been $89.98 \mathrm{~km}$, this distance was used to calculate the corresponding race times and presented in Table II.

Shvetsov would have been a staggering 5 minutes ahead in our hypothetical race, demonstrating clearly what a superb run he had in 2007. Note, too, how close the two fastest times by Fordyce are, 
TABLE I. Running speed in time per kilometre of the fastest 'down' Comrades marathon runners

\begin{tabular}{llllcc}
\hline Rank & Runner & Year & Distance & Race time $(\mathbf{h : m i n : s )}$ & Speed $\left(\mathbf{m i n}^{\mathbf{s}} \mathbf{s . \mathbf { k m } ^ { - 1 } )}\right.$ \\
1 & L Shvetsov & 2007 & 89.30 & $5: 20: 41$ & $3: 35.5$ \\
2 & B Fordyce & 1984 & 89.75 & $5: 27: 18$ & $3: 38.8$ \\
3 & B Fordyce & 1986 & 88.77 & $5: 24: 07$ & $3: 39.1$ \\
4 & A Robb & 1978 & 90.10 & $5: 29: 14$ & $3: 39.2$ \\
5 & C Mattheus & 1997 & 89.90 & $5: 28: 37$ & $3: 39.3$ \\
6 & B Fordyce & 1982 & 91.40 & $5: 34: 22$ & $3: 39.5$ \\
\hline
\end{tabular}

and that the sixth time on the list by Fordyce is only just over a minute slower than his fastest time, suggesting strongly that the times run by Fordyce were probably close to his genetic limits. If the time and speed of the fifth best performer, Kelehe $\left(3: 39.7 . \mathrm{km}^{-1}\right)$ are included, his time would be 5:29:27.

If we examine the times (h:min:s) for the 'up' run, a similar picture emerges. The five fastest times for the 'up' run are:
1. L Shvetsov
5: 24: 49 (2008)
2. V Kotov
5: 25: 33 (2000)
3. D Grishine
5: $26: 25$ (1998)
4. A Volgin
5: 27: 07 (2000)
5. B Fordyce
5: $27: 42$ (1988)
6. D Grishine
5: 29: 33 (1996)

As with the 'down' run, a performance based on running speed can be calculated (Table III).

When expressed as time per kilometre, the ranking of the fastest six runners changes somewhat. Although Shvetsov remains the best performer, his dominance in the 'up' is less than in the 'down' run. Here his time is $0.5 \mathrm{~s} . \mathrm{km}^{-1}$ faster than Fordyce, compared with the

of the race, the dominance of Fordyce in the Comrades marathon is apparent even 18 years since his last victory in 1990. Striking, too, is the performance in 1978 of Robb, which must now be considered to have been ahead of its time. Returning to more recent years, however, we must recognise the greatness of runs such as that by

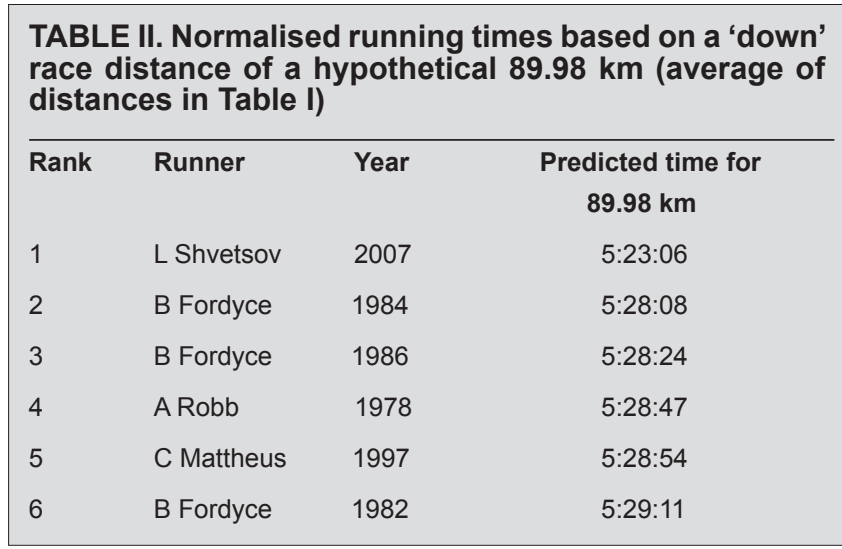

\section{TABLE III. Running speed in time per kilometre of the fastest 'up' Comrades Marathon runners}

\begin{tabular}{llllll}
\hline Rank & Runner & Year & Distance & Race time (h:min:s) & Speed $\left(\mathbf{m i n}: \mathbf{s . k m}{ }^{-1}\right)$ \\
1 & L Shvetsov & 2008 & 86.94 & $5: 24: 49$ & $3: 44.2$ \\
2 & B Fordyce & 1988 & 87.5 & $5: 27: 42$ & $3: 44.7$ \\
3 & V Kotov & 2000 & 86.55 & $5: 25: 33$ & $3: 45.9$ \\
4 & B Fordyce & 1983 & 87.7 & $5: 26: 25$ & $3: 46.3$ \\
5 & D Greshin & 1998 & 86.55 & $5: 27: 07$ & $3: 46.8$ \\
\hline
\end{tabular}

considerable 3 seconds per km in the 'up' run. Fordyce again shows his dominance in the race, being the only athlete to have two of the fastest times on the all-time top-six list. He and Shvetsov are the only runners to appear on both lists, and Fordyce is the only runner to appear more than once on both lists. Interestingly, it is only Fordyce and Shvetsov who have achieved a running speed of over $16 \mathrm{~km} . \mathrm{hr}^{-1}$ on the 'up' run.

The average distance of the 'up' races in Table III is $86.97 \mathrm{~km}$. As with the 'down' run, this distance can be used to calculate normalised hypothetical times using the running speed of each runner from Table III. The predicted race times are shown in Table IV.

Unlike the 'down' race, the 'winning' margin by Shvetsov is not as big for the 'up' run, 'winning' by just 43 seconds. One could speculate whether 20 years of technological improvement and gains in knowledge can account for those 43 seconds. Whereas 6 minutes separated the best and sixth best performance in the down race, the gap is less than half of that for the 'up' run.

The lack of top times by South Africans in the 'up' race is obvious. While there have been some great performances in the recent history

\begin{tabular}{|c|c|c|c|}
\hline \multicolumn{4}{|c|}{$\begin{array}{l}\text { TABLE IV. Normalised running times based on an 'up' } \\
\text { race distance of a hypothetical } 86.97 \mathrm{~km} \text { (average of } \\
\text { distances in Table III) }\end{array}$} \\
\hline Rank & Runner & Year & $\begin{array}{l}\text { Predicted time for } \\
\quad 86.97 \mathrm{~km}\end{array}$ \\
\hline 1 & L Shvetsov & 2008 & $5: 24: 59$ \\
\hline 2 & B Fordyce & 1988 & $5: 25: 42$ \\
\hline 3 & V Kotov & 2000 & $5: 27: 05$ \\
\hline 4 & B Fordyce & 1983 & $5: 27: 27$ \\
\hline 5 & D Greshine & 1998 & $5: 28: 05$ \\
\hline 6 & A Volgin & 2000 & $5: 28: 42$ \\
\hline
\end{tabular}

Kotov in 2000, his victory as a 46-year-old in the 2004 race, and his eighth place at the age of 50 in the race this year (2008), which must count as one of the great performances in the history of the race. 